\title{
A Knee-Point-Based Evolutionary Algorithm Using Weighted Subpopulation for Many-Objective Optimization
}

\author{
Juan Zou ${ }^{\mathrm{a}, \mathrm{c}}$, Chunhui Ji ${ }^{\mathrm{a}, \mathrm{f}, *}$, Shengxiang Yang ${ }^{\mathrm{a}, \mathrm{d}, *}$, Yuping Zhang ${ }^{\mathrm{a}, \mathrm{b}}$, Jinhua \\ Zheng ${ }^{\mathrm{a}, \mathrm{c}}, \mathrm{Ke} \mathrm{Li}^{\mathrm{e}}$ \\ ${ }^{a}$ Key Laboratory of Intelligent Computing and Information Processing, Ministry of \\ Education, Information Engineering College of Xiangtan University, Xiangtan, Hunan \\ Province, China \\ ${ }^{b}$ LED Lighting Research 85 Technology Center of Guizhou TongRen, GuiZhou, China \\ ${ }^{c}$ Hunan Provincial Key Laboratory of Intelligent Information Processing and Application, \\ Hengyang, 421002, China \\ ${ }^{d}$ School of Computer Science and Informatics, De Montfort University, Leicester LE1 \\ $9 B H, U . K$. \\ ${ }^{e}$ College of Computer Science and Engineering, University of Electronic Science and \\ Technology of China, Chengdu, 611731, China \\ ${ }^{f}$ Key Laboratory of Hunan Province for Internet of Things and Information Security.
}

\begin{abstract}
Among many-objective optimization problems(MaOPs), the proportion of nondominated solutions is too large to distinguish among different solutions, which is a great obstacle in the process of solving MaOPs. Thus, this paper proposes an algorithm which uses a weighted subpopulation knee point. The weight is used to divide the whole population into a number of subpopulations, and the knee point of each subpopulation guides other solutions to search. Additionally, the convergence of the knee point approach can be exploited, and the subpopulation-based approach improves performance by improving the diversity of the evolutionary algorithm. Therefore, these advantages can make the algorithm suitable for solving MaOPs. Experimental results show that the proposed algorithm performs better on most test problems than six other state-of-the-art many-objective evolutionary algorithms.
\end{abstract}

\footnotetext{
${ }^{*}$ Corresponding author: Chunhui $\mathrm{Ji}$ Yang)

Email addresses: 2372552966@qq.com (Chunhui Ji), syang@dmu.ac.uk (Shengxiang
}

Preprint submitted to Journal of $\mathrm{L}^{A} T_{E} X$ Templates

February 24, 2019 
Keywords: knee point, many-objective optimization, decomposition, convergence, diversity

\section{INTRODUCTION}

In the real world, multiobjective optimization problems (MOPs) 1 involve at least two conflicting objectives. A MOP which has as least four objectives is referred to as a many-objective optimization problem(MaOP) [1]. There are many applications of these problems, such as in the design of water resources allocation systems [2], standard settings for automotive engines [3] and engineering resource scheduling [4. Due to the failure of Pareto-dominance and the necessity of expensive investment when using traditional algorithms to solve $\mathrm{MaOPs}$, researchers have used evolutionary algorithms (EA) to solve these kind$\mathrm{s}$ of problems. 5. From this research, a series of many-objective evolutionary algorithms(MaEAs) has been proposed.

Traditional algorithms, such as NSGA-II [6], SPEA-II [7, PESAII [8] and others [9, 10, 11, 12, 13, have used Pareto dominance to distinguish between different individuals. This is because Pareto-based nondominated sorting approaches can select a solution which has better performance in the population or in mixed populations. However, the efficiency of Pareto-dominance gradually declines as the number of objectives increases. The proportion of non-dominated individuals in the population is then too large to converge. When the problem has more than eight objectives, Pareto-dominance will be completely ineffective [5.

To enhance the performance of traditional MOEAs in handling MaOPs, many algorithms have been proposed, which can be split into six categories [1]. The first category is the relaxed-dominance-based approach. The main idea of this approach is to weaken the conditions for judging dominate relations to enhance the ability to select excellent solutions. There are many algorithms of this type, such as $\epsilon$-MOEA [14, CDAS 15] and GrEA [16. In $\epsilon$-MOEA, the objective space is divided into grids, and grid dominance is used to replace 
Pareto dominance. This type of strategy increases the scope of domination and distinguishes dominated solutions from nondominated ones. A method to control the dominance area of solutions was proposed by Sato et al. 15 to adjust the selection pressure, thus changing the algorithm convergence. In GrEA, a grid-based evolutionary algorithm was proposed to optimize MaOPs [1]. Three criteria - grid ranking(GR), grid crowding distance(GCD) and grid coordinate point distance(GCPD) — were integrated into GrEA [16] to select solutions in the process of mating or environmental selection. Based on the adaptive construction of grids, the selection pressure was increased by grid dominance. Test problems demonstrated that the relaxed-dominance-based algorithm has a certain competitive ability; However, because the set of relaxation degrees is according to the decision maker, it is hard to determine an exact value and reach the ideal state.

The second category is the well-known diversity-based approach. Diversity is used as a criterion for evaluating algorithms and is often used as a selection strategy within the critical layer [6]. It has been shown that diversity-based algorithms, such as DM [17, SDE [18] and 1by1EA [19, express excellent performance. In SDE, the shift operation pushes poorly converged solutions into crowded regions, so this approach can balance convergence and diversity. In DM, whether to activate the diversity promotion or not is according to the distribution of the population. When the population is excessively dispersed, diversity promotion is closed. As proven by S. F. Adra [17, the improved algorithm performs better than the original one. In 1 by1EA, the selection of offspring individuals is based on a computationally efficient convergence indicator. Meanwhile, the neighbors of the selected individual are de-emphasized to guarantee the diversity of the population.

The third category is the aggregation-based method. MSOPS [20, DQGA 21] and MOEA/D 22] are the classical algorithms of this type. Zhang and Li 22. proposed a decomposition-based algorithm named MOEA/D. In MOEA/D, the neighbors of a solution are valuable to the solution. First, the vertical distance between the weight vectors is calculated, and a part of the vector near 
each weight vector is found. Then, all the weight vectors are assigned solutions respectively. Finally, the population is updated by the aggregate function value of the new solution. Weighted sum, weighted Tchebycheff and boundary intersection methods are commonly used as aggregation function [22]. In MSOPS, Hughes [20] proposes that all solutions in the population be sorted according to vector angle distance scaling and weighted Tchebycheff methods.

The fourth category includes performance-indicator-based approaches. Considering that the performance indicator is a criterion of the evaluation algorithm, the indicator-based approach is the most straightforward method. This type of algorithm includes HypE [23], SMS-EMOA [24], and IBEA [25]. Performanceindicator-based algorithms have good performance in solving MaOPs; however, their computational load increases exponentially when the number of objectives increases.

The fifth category contains reference-set-based algorithms. These algorithms use a set of reference points to guide the search direction of the population. Examples of this type of algorithm include NSGA-III [26], TAA [27], TC-SEA [28] and VaEA [29]. In NSGA-III, an association operation is used to associate a reference point with a solution; then the solutions that are associated with the same weight can be operated as a niche. TAA divides the population into two parts, taking advantage of the historic and current populations' information to construct the reference set and guide the search. In VaEA, two principles, maximum-vector-angle-first principle and worse-elimination principle, were adopted to guarantee the quality of the solution set. The former guarantees a good performance in terms of spread and distribution of the solution set, the latter ensures that the worst solutions in terms of convergence can be conditionally replaced by other individuals.

The sixth category includes dimensionality reduction approaches. This type of algorithm includes L-PCA [30], CDR [11] and SSR [31]. In solving MaOPs, some redundant objectives are merged. When a MaOP with high dimensions has a similar Pareto front $(\mathrm{PF})$ to another problem with low-dimensions, we can try to optimize the lower-dimensional problem instead of the original one. 
This paper proposes a knee-point-based evolutionary algorithm using a weighted subpopulation for many-objective optimization(WSK). The core of the proposed algorithm is to guide the search direction of the population through the knee point of the subpopulation. Uniform weights are used to classify populations into different subpopulations and calculate the distance between solution and hyperplane. The solution with the shortest hyperdistance is considered to be the knee point. Every knee point represents the best performance in its subpopulation. These knee points are used to guide the population to search in the direction of the PF. This algorithm is very competitive when compared to other state-of-the-art algorithms.

\section{RELATED WORK}

In decomposition-based algorithms, a number of weight vectors convert a MOP into a set of single objective problems(SOPs) through a scalar function which is then optimized separately. The global optima can be obtained by combining the solutions of the SOPs. Zhang and Li 22] proposed MOEA/D, which decomposes a MOP into a number of scalar subproblems and optimizes them simultaneously. To start, a set of weight vectors $\vec{w}\left(w_{1}, w_{2}, \cdots, w_{m}\right)$ is generated, and the neighbor structure is established for every weight vector. The solution associated with the weight can use the neighborhood information to promote evolution. This kind of algorithm usually has two benefits: 1)decreasing the complexity of computation and 2)using the shared information of neighbors. However, these algorithms, which rely on aggregate function, to be removed, which have better values in Pareto-dominance but worse values in aggregation function.

An example of an aggregate function value calculation is described in Figure

1. The $d_{1}$ is Euclidean distance from perpendicular to the origin, and the $d_{2}$ is Euclidean distance from perpendicular to the individual P. These parameters 

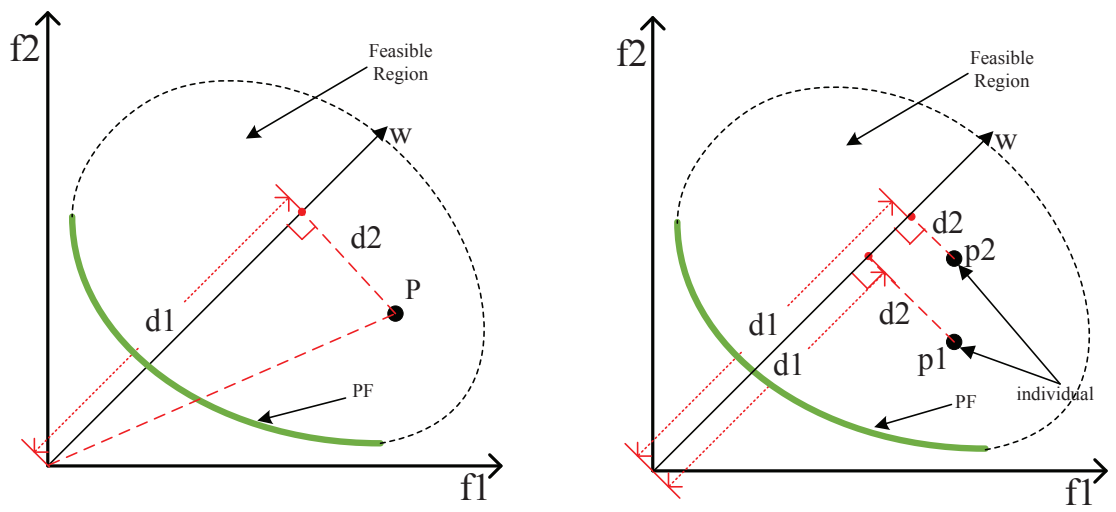

Figure 1: Illustration of the penalty-based Figure 2: Illustration of the update operation. boundary intersection approach in MOEA/D.

117

can be computed respectively as follows:

$$
\begin{gathered}
d_{1}=\frac{\left\|f(x) \cdot w_{j}\right\|}{\left\|w_{j}\right\|} . \\
d_{2}=\left\|f(x)-d_{1}\left(w_{j} /\left\|w_{j}\right\|\right)\right\| . \\
A F=d_{1}+\theta * d_{2},
\end{gathered}
$$

118

where the $\theta$ is set by the decision maker and $A F$ is the aggregate function value of the solution. It can be seen in Figure 2 that individual $p_{1}$ will more likely be replaced by individual $p_{2}$ according to the aggregate function value, yet, $p_{1}$ has better convergence than $p_{2}$.

To solve this problem, we propose using the knee point selection strategy instead of the aggregate function value strategy. This effectively prevents the optimal solution from being replaced by the inferior solution. The knee point is the most critical point on the PF. There are many methods to choose the knee point. For example, you can see a knee point selection based on the angle 32 in Figure 3. Slopes of the two lines through an individual and its two neighbors 


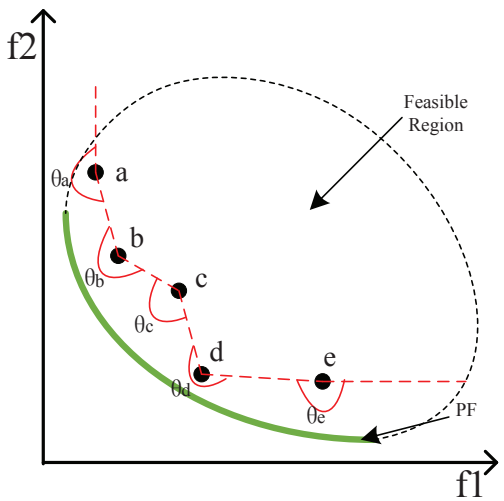

Figure 3: Illustration for determining knee point by angle for a bi-objective minimization problem.

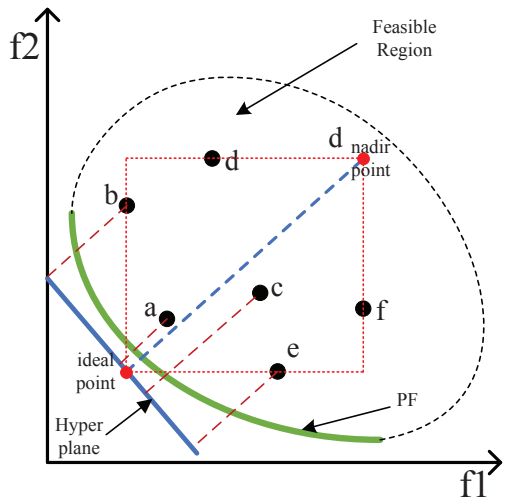

Figure 4: Illustration for determining knee point by distance for a bi-objective minimization problem.

are shared, and then the angle between these slopes is regarded as a criterion of whether the individual is at a knee or not. It is obvious that the angle $\theta_{d}$ is the largest among all of the angles, so solution $d$ is chosen as the knee point. Another method for selecting knee points is based on the distance from the point to hyperplane [33. Using the ideal point and nadir point to construct a hyperplane, the vertical distance of all solutions to the hyperplane is calculated. The solution with the shortest vertical distance is chosen as the knee point. Take two objective problems as an example, such as Figure 4 , the solution with the shortest distance will be the knee point.

Of the aforementioned methods, the first uses the angle of the adjacent solution on both sides, meaning it cannot be applied to MaOPs because adjacent angles are unsure. Thus, we choose the latter as the way to calculate the knee point. In the KnEA [33], the knee point is selected from solutions of the same Pareto layer. The solutions around the knee point are eliminated until all knee points of the same Pareto layer are found. Even though the region exclusion method is adopted, the population still easily falls into the marginal region. This method can make full use of the solution's convergence, but the diversity 


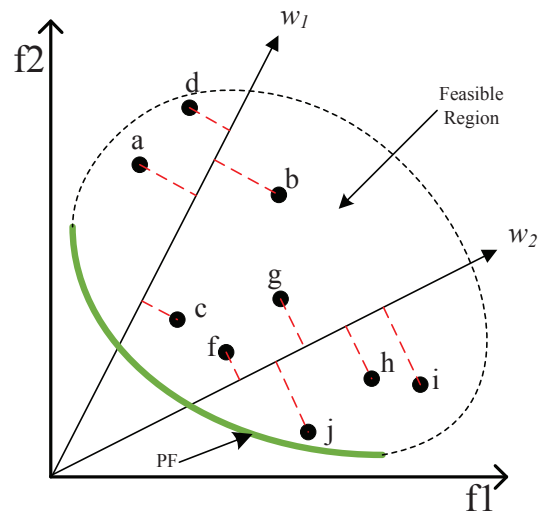

Figure 5: Illustration of repartition operation in WSK.

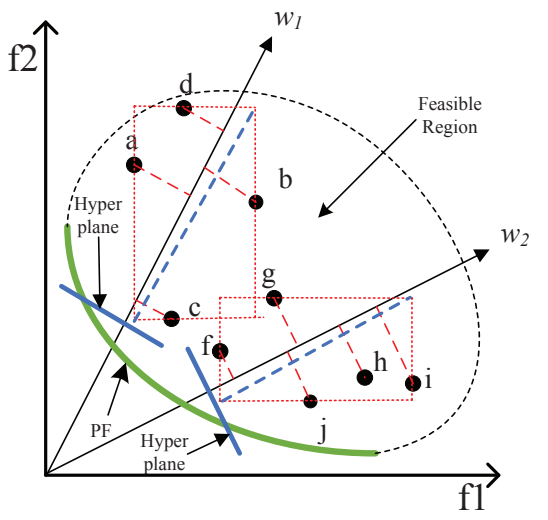

Figure 6: Illustration for determining knee point of subpopulation by distance for a biobjective minimization problem.

is not as good as the former.

In order to maximize the performance of the knee point, this paper proposes an algorithm to introduce the concept of knee point to subpopulation. The distance from solution to weight is computed to associated solution with weight. In every subpopulation, the line through an ideal point and a nadir point is used to construct a hyperplane. The distance from solution to hyperplane can be regarded as a criterion of whether the individual is at a knee or not. As in Figure 5 and Figure 6, the whole population is divided into a set of subpopulations, and the knee point is found in every subpopulation. We can see each subpopulation has its own standard for calculating knee point rather than the unified formula of MOEA/D.

\section{PROPOSED ALGORITHM: WSK}

The key task of WSK is to find the knee point of the subpopulation. As in [33, the subpopulation knee point can be defined as follows:

Definition of subpopulation knee point: An individual is considered to be a knee point if and only if it has the shortest vertical distance from the 


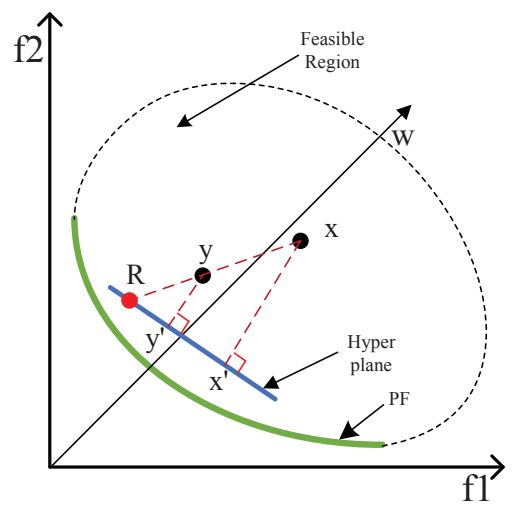

Figure 7: Illustration of the uniqueness of the knee point in the subpopulation.

individual to the hyperplane among the subpopulation.

According to this definition, the subpopulation's knee point has the following properties:

Property: If $x$ is the knee point, it cannot be Pareto-dominated by other individuals in the subpopulation.

Proof: Let us use a specific example shown in Figure 7 to prove this definition. Suppose $x$ is knee point and $y$ Pareto-dominates $x$. Connecting $x$ and $y$, it can be seen that vertical line $y y^{\prime}$ is parallel with vertical line $x x^{\prime}$. According to the similarity theorem of triangles, $R y y^{\prime} \sim R x x^{\prime}$ (Triangle $R y y^{\prime}$ is similar to Triangle $\left.R x x^{\prime}\right)$. Since $R y<R x$, we can derive that $y y^{\prime}<x x^{\prime}$. Obviously, the result contradicts the hypothesis. Therefore, the property is reasonable.

\subsection{General Framework of the Proposed Algorithm}

The general framework of WSK consists of three parts: (1) Initialization, which mainly aims to initialize a population; (2) Mating selection, which is to select $N$ individuals for evolutionary operations through the binary tournament selection. (In binary tournament selection, three criteria are adopted, namely, the dominance relationship, the knee point judge and the crowding degree.) (3) 
Environmental selection, which selects $\mathrm{N}$ individuals as the parent population of the next generation. This procedure is repeated until the termination condition is satisfied and the pseudocode of the general framework of WSK is shown in Algorithm 1 .

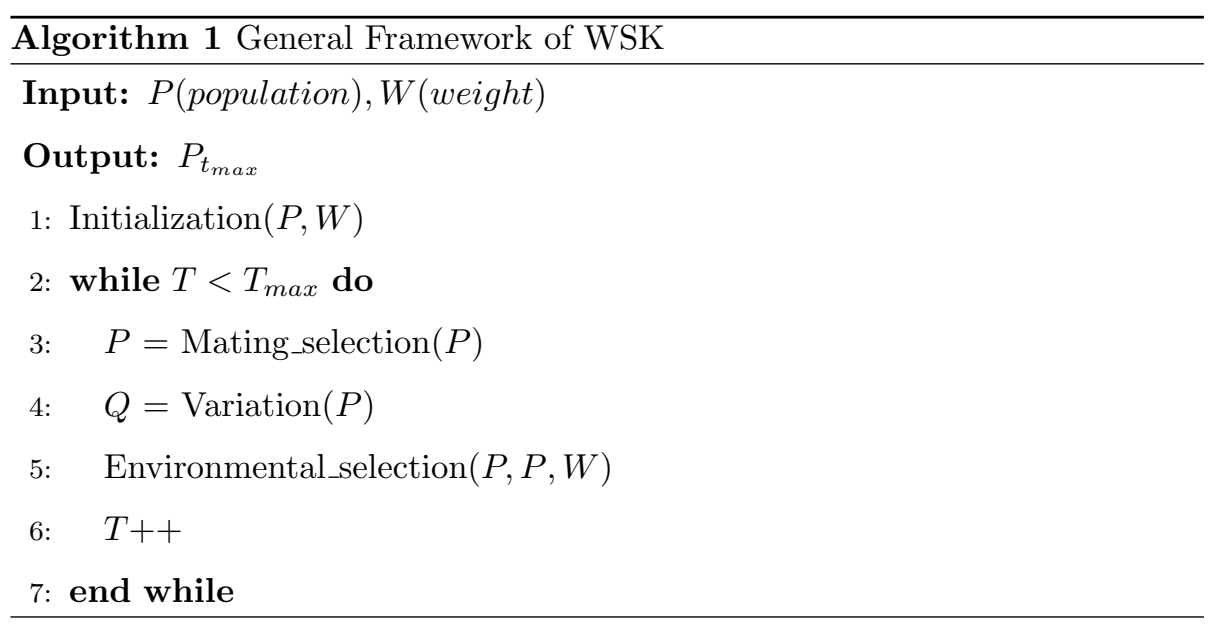

\subsection{Mating Selection}

The binary tournament selection has three competitive strategies. First, two solutions are randomly chosen from the population. If one solution dominates the other solution, the former is chosen. If there is no dominance relation between the two solutions, individuals are checked to see whether they are knee points or not. If one solution is a knee point and the other solution is not, the former is chosen; otherwise, a third strategy is used. Next, the crowding degrees between the two individuals are compared, and the bigger one was is selected. The crowding degree is the sum of the angles between the solution and the nearest two individuals. Finally, if the above conditions are all invalid, a solution will be chosen randomly. The pseudocode of mating selection is shown in Algorithm 2

\subsection{Environmental Selection}

Environmental selection is to select solutions to form the next generation of the population. Unlike other MOEAs with a nondominated sort, WSK does 


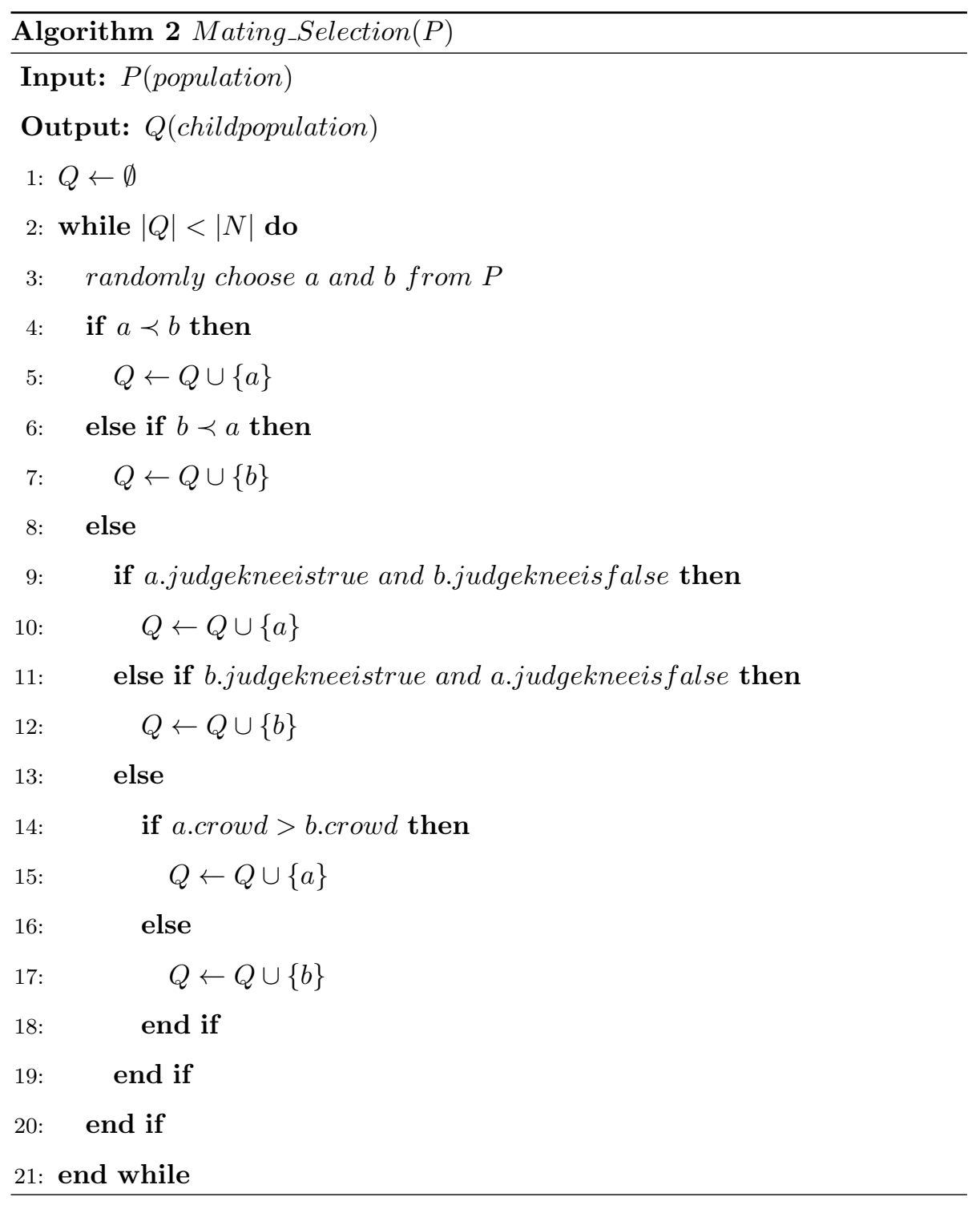

not use nondominated sorting but elite replacement. The elite replacement strategy is to replace the original population with the elite solutions of the new population. Before environmental-selection operation, some strategies are used. Normalization is used to compress the population into the standard space. The repartition operation finds the nearest weight through min angle between solution and weight. Hyperdistance represents the performance of a solution. 
The details of environmental selection of WSK are presented in Algorithm 3

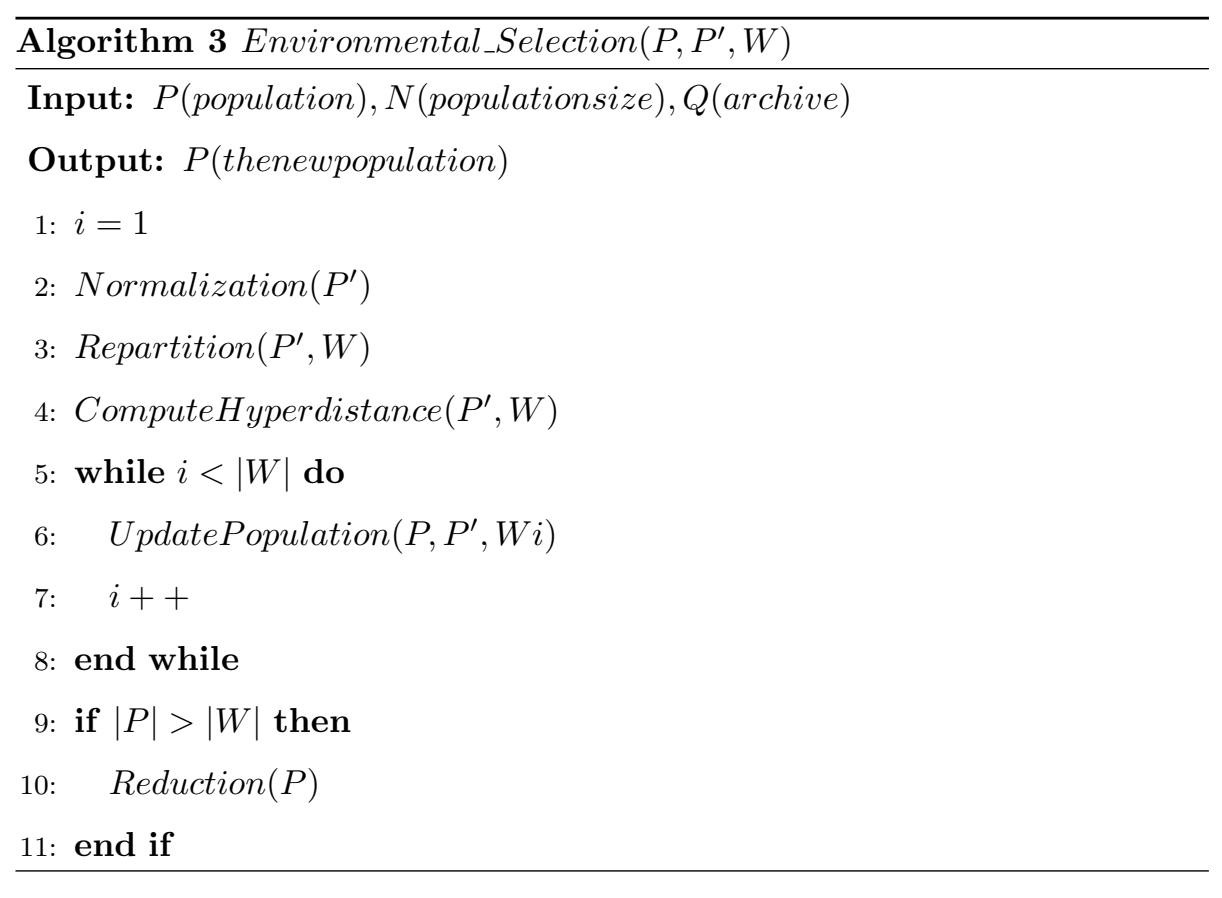

1) Normalization: The procedure of normalization is shown in Algorithm 4 . First, the ideal point $Z_{\min }=\left(z_{1}^{\min }, z_{2}^{\min }, \ldots, z_{m}^{\min }\right)$ and nadir point $Z_{\max }=$ $\left(z_{1}^{\max }, z_{2}^{\max }, \ldots, z_{m}^{\max }\right)$ are found, where the $Z_{\min }$ and $Z_{\max }$ denote the minimal and maximal objective values in each objective function, respectively. Then the solutions in the populations are normalized to standard space through the following formula:

$$
f_{i}^{\prime}\left(x_{j}\right)=\frac{f_{i}-Z_{i}^{\min }}{Z_{i}^{\text {max }}-Z_{i}^{\min }}, i=1,2, \ldots, m .
$$

Here the $f_{i}^{\prime}\left(x_{j}\right)$ is the transformed objective value.

2) Repartition: After the transformation of objective space, the repartition operation can be executed in transformed objective space. The angle between solution and weight are used to find the nearest weight of each solution in the population. The formula for calculating angles is as follows:

$$
\cos \theta=\frac{F_{i}(x) \cdot W_{j}(x)}{\left|F_{i}(x)\right| \cdot\left|W_{j}(x)\right|}, i=1,2, \ldots, m .
$$




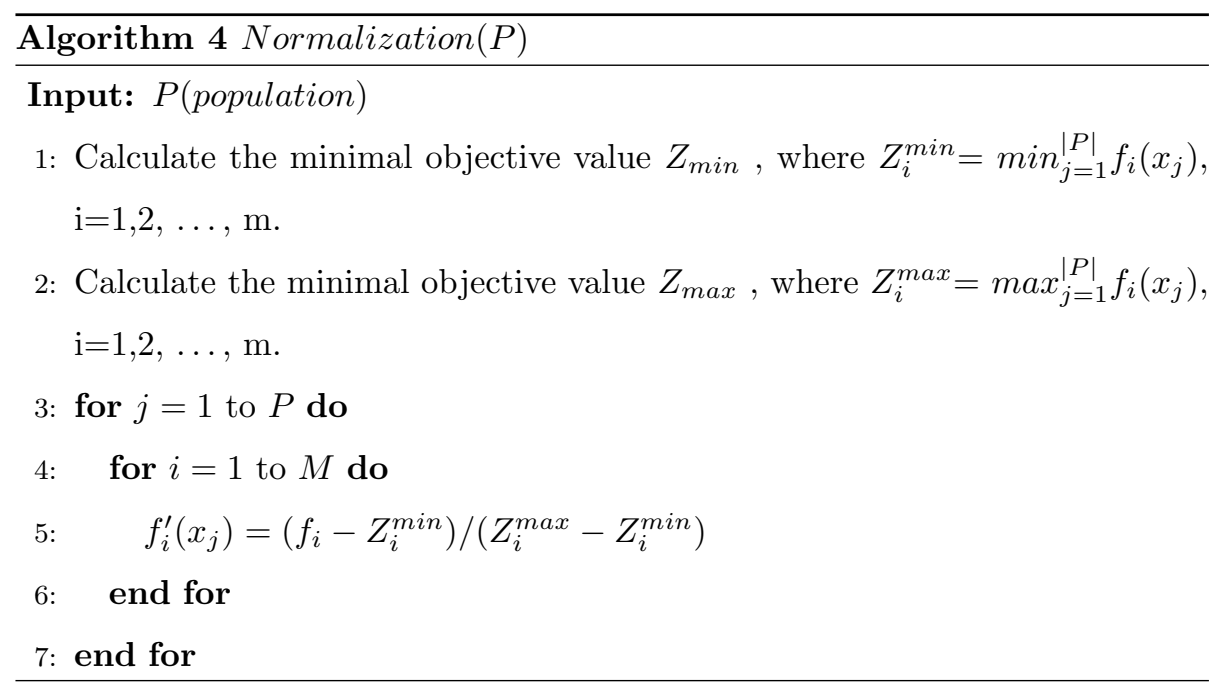

Here $F_{i}(x) \cdot W_{j}(x)$ return the inner product between $F_{i}(x)$ and $W_{j}(x)$. The angle value is between zero and one. This procedure is shown in Algorithm5.

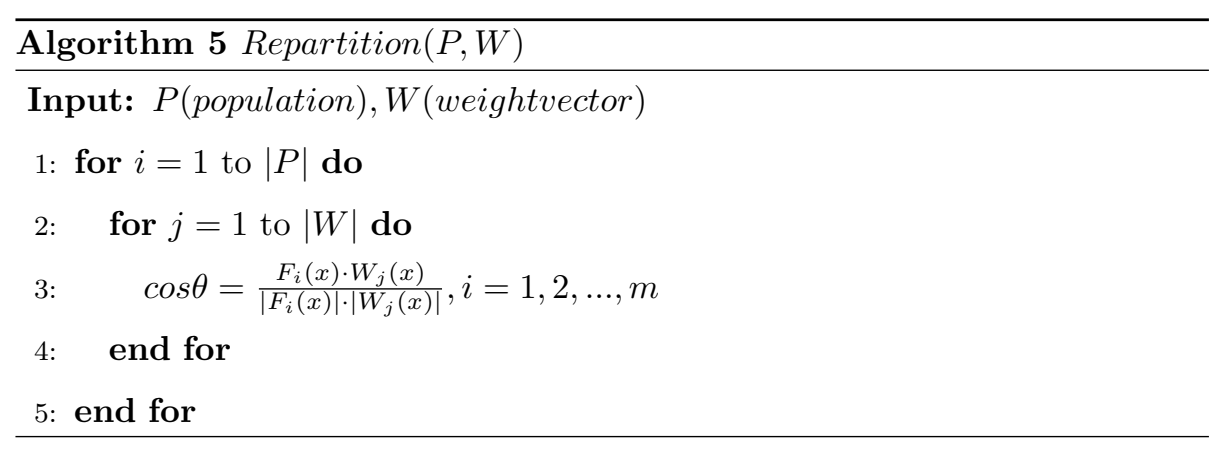

3) Compute Hyperdistance: The computation of hyperdistance is executed in each subpopulation. By computing the direction of the ideal point and nadir point, the normal vector of the hyperplane can be obtained. The solution in the subpopulation needs to be calculated by taking the distance from the point to hyperplane and the distance from the point to normal vector. The sum of the two distances is used to indicate fitness value.

4) Update Population: The new population and original population need not be merged, but the old population is updated by the new population. We need to compare the distribution of new and old populations on the same weight. 


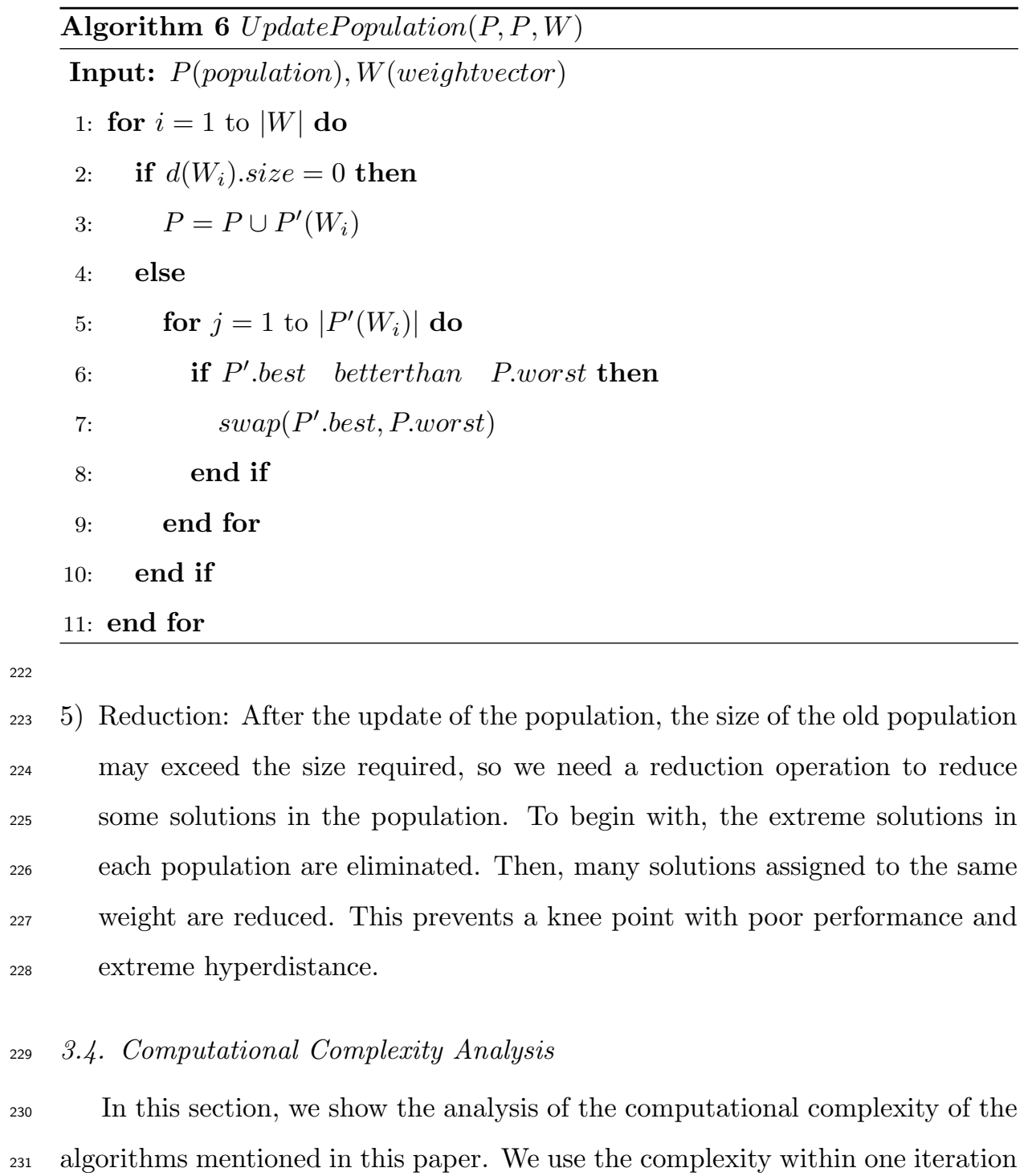




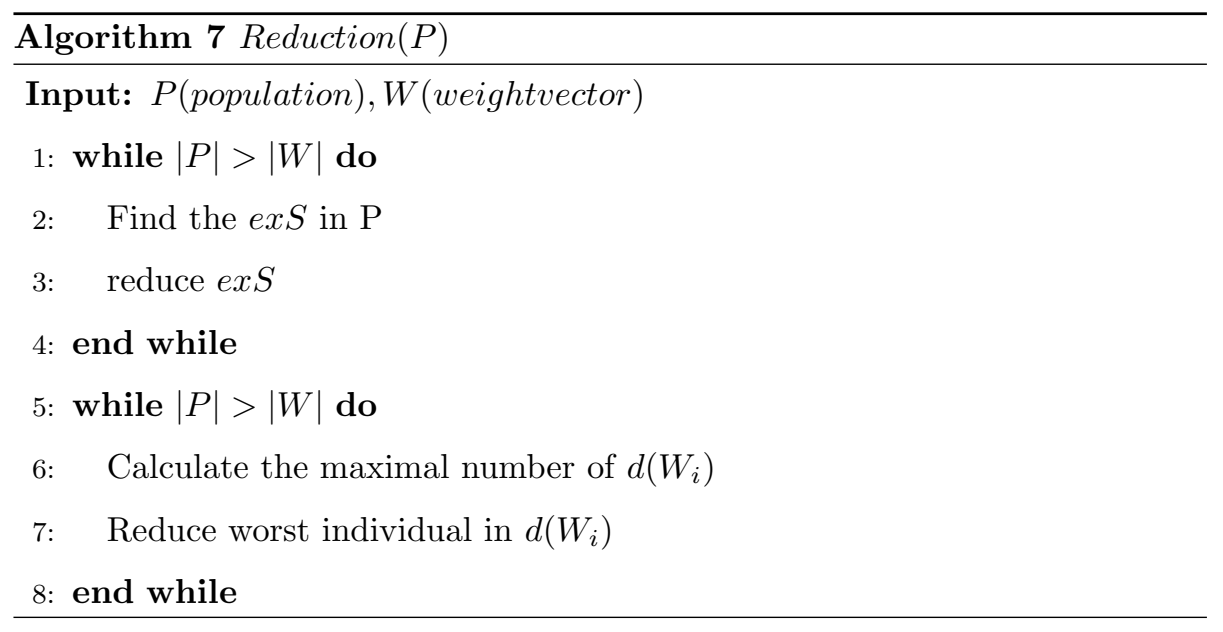

as the complexity of the algorithm. For a population size $N$ and optimization problem of $M$ objectives, the repartition operation has time complexity $\mathrm{O}\left(M N^{2}\right)$. Finding the ideal point and nadir point require a total of $\mathrm{O}(M N)$ computations. The update operation has a time complexity of $\mathrm{O}\left(M N^{2}\right)$. For computing the operation of hyperdistance, a runtime of $\mathrm{O}(M N)$ is needed. Therefore, the overall complexity of one generation in WSK is $\mathrm{O}\left(M N^{2}\right)$. Compared with recent popular MaEAs, the computational complexity of WSK is considerable.

\subsection{Discussion}

In MOEA/D, NSGA-III and WSK, each population member is associated with a reference line based on the perpendicular distance that could be measured by angles to some extent. Notably, both ways consider the relation between the individual and the reference line, which has no obvious difference in validity and performance.

Consider the neighborhood concept. MOEA/D makes full use of the neighbor's information, but the probability that the population falls into the local optima increases. Different from MOEA/D, which uses a scalar function to measure the convergence of a solution, WSK introduces the concept of a subpopulation knee point, where the subpopulation knee point represents the best 
convergence in the subpopulation. Meanwhile, one of the major differences between the two algorithms is that WSK does not convert a MOP into a number of scalar optimization subproblems. In NSGA-III, the perpendicular distance between the individual and the reference line is served as either convergence or diversity. Therefore, the NSGA-III has more difficulty converging than other algorithms.

Unlike other algorithms such as KnEA and NSGA-III, which are based on the nondominated sort, WSK uses elite replacement. The elite replacement strategy replaces the original population with the elite solutions of the new population. The subpopulation knee point used in WSK is different from KnEA. Even though it has the same calculation method, the subpopulation knee point is defined for each subpopulation and each one is unique, while the knee point in KnEA is defined for the whole population and the number of knee points increases with the evolution.

\section{SIMULATION RESULTS}

In this section, the performance of WSK is verified experimentally. We compared WSK with seven state-of-the-art MaEAs for MaOPs, namely, SPEA2+SDE 18, MOEA/D 22, MSOPS [20, NSGA-III 26], GrEA [16], HypE [23] and KnEA [33] on the WFG 34, DTLZ 35] and ZDT [36] test suites.

\subsection{Experimental Setting}

For fairness, general parameters are used in this paper. Parameters were set as follows:

1) Crossover and Mutation: The recommended SBX [37 and polynomial mutation [38] were adopted to generate offspring. The distribution index $n_{c}$ of crossover was set to 20 , and the crossover probability $p_{c}$ was set to 1.0 . Similarly, the distribution index $n_{m}$ of mutation was set to 20 , and the mutation probability $p_{m}$ was set to $1 / n$, where $n$ denotes the number of decision variables. 
Table 1: Setting of population size

\begin{tabular}{cccc}
\hline $\mathrm{M}$ & $\mathrm{H}$ & NSGA-III & $\begin{array}{c}\text { MOEA/D } \\
\text { WSK }\end{array}$ \\
\hline 3 & 91 & 92 & 91 \\
5 & 210 & 212 & 210 \\
8 & $156(\mathrm{~h} 1=3, \mathrm{~h} 2=2)$ & 156 & 156 \\
10 & $275(\mathrm{~h} 1=3, \mathrm{~h} 2=2)$ & 276 & 275 \\
15 & $135(\mathrm{~h} 1=2, \mathrm{~h} 2=1)$ & 136 & 135 \\
\hline
\end{tabular}

2) Population Size: The strategy of two-layered reference points in NSGAIII 26] was adopted to generate a set of uniformly distributed weight vectors. Table 1 shows the setting of population size in MOEA/D and NSGA-III.

3) Number of Runs and Termination Condition: All algorithms were independently run 30 times on each test instance according to the parameter conditions. The setting of maximum function evaluations (MFEs) can be seen in Table II. For different numbers of objectives, the termination condition can be calculated by $T_{\max }=\mathrm{MFE} / \mathrm{N}$.

\subsection{Performance Metrics}

In our experiment, two quality indicators were adopted to compare the performance of different algorithms. Both Inverted Generational Distance(IGD) [39] and Hypervolume (HV) 40] can provide the information of convergence and distribution of the algorithm simultaneously, have been accepted by peers and are used as a common measure of algorithm performance evaluation.

1) IGD: This metric represents the mean distance between the solution on the true $\mathrm{PF}$ and the nearest solution in the population. Let $\mathrm{P}$ be a set of points uniformly distributed on the true $\mathrm{PF}$, and $P^{\prime}$ be a set of points in the population. For IGD, the smaller value is preferable, which indicates that the solution set is close to the true PF and has a good distribution. The IGD metrics are defined as follows:

$$
I G D=\frac{1}{\left|P^{\prime}\right|} \sum_{z \in P^{\prime}} \operatorname{dist}(z, P)
$$


2) HV: This metric calculates the volume between the solution in the population and the given reference point. A key issue that must be addressed to calculate the $\mathrm{HV}$ indicator is the choice of the reference point. The objective value of the population is normalized into the standard space according to the range of the problems' PFs. Similarly, the reference point is set to 1.1 times the upper bound of the true PFs. We used Monte Carlo sampling[23] to evaluate the performance of the algorithms. For HV, the bigger value is preferable.

To have statistically comprehensive conclusions, the Wilcoxon's Rank test 41 . at a 0.05 significance level was adopted to test the significant difference between the data obtained by paired algorithms.

\subsection{Results and Analysis}

The WFG test suite [34] is a set of widely used benchmark problems. These test problems have various properties, such as having a concave, convex, mixed, discontinuous, or degenerate PF and having a multimodal, biased or deceptive search space. HV results in terms of the mean and standard deviation of the MaEAs are shown in Table 2. As can be seen from the table, WSK performed outstanding on all test problems except for WFG1. WFG1 has a mixed PF and a biased search space. For WFG1, the performance of WSK is general and SDE achieved the best HV value on all numbers of objectives. This occurrence may be because the mixed PF affects the selection of the subpopulation knee point. WFG2 has a convex and discontinuous PF. For WFG2, WSK achieved the best $\mathrm{HV}$ values on 8-objective and 10-objective problems and achieved the second best $\mathrm{HV}$ value on 3-objective and 5-objective problems. WFG3 has a degenerate PF. WSK performs better than other algorithms on WFG2 with all numbers of objectives except for 3 .

For the other problems, different algorithms have their own strengths. Six test problems, from WFG4 to WFG9 have a concave PF. For WFG4 and WFG8, WSK obtained the best HV value on three test instances and obtained the second best $\mathrm{HV}$ value on three test instances. From the statistics, WSK is slightly inferior to SDE and NSGA-III. For WFG5, WFG6, WFG7 and WFG9, WSK 
Table 2: HV (mean and standard deviation) results of the five algorithms on the WFG suites, where the best mean is shown with a deep gray background and the second best with a light gray background.

performed better than the other algorithms. As we can see from the statistics, WSK had excellent performance when dealing with asymmetric problems.

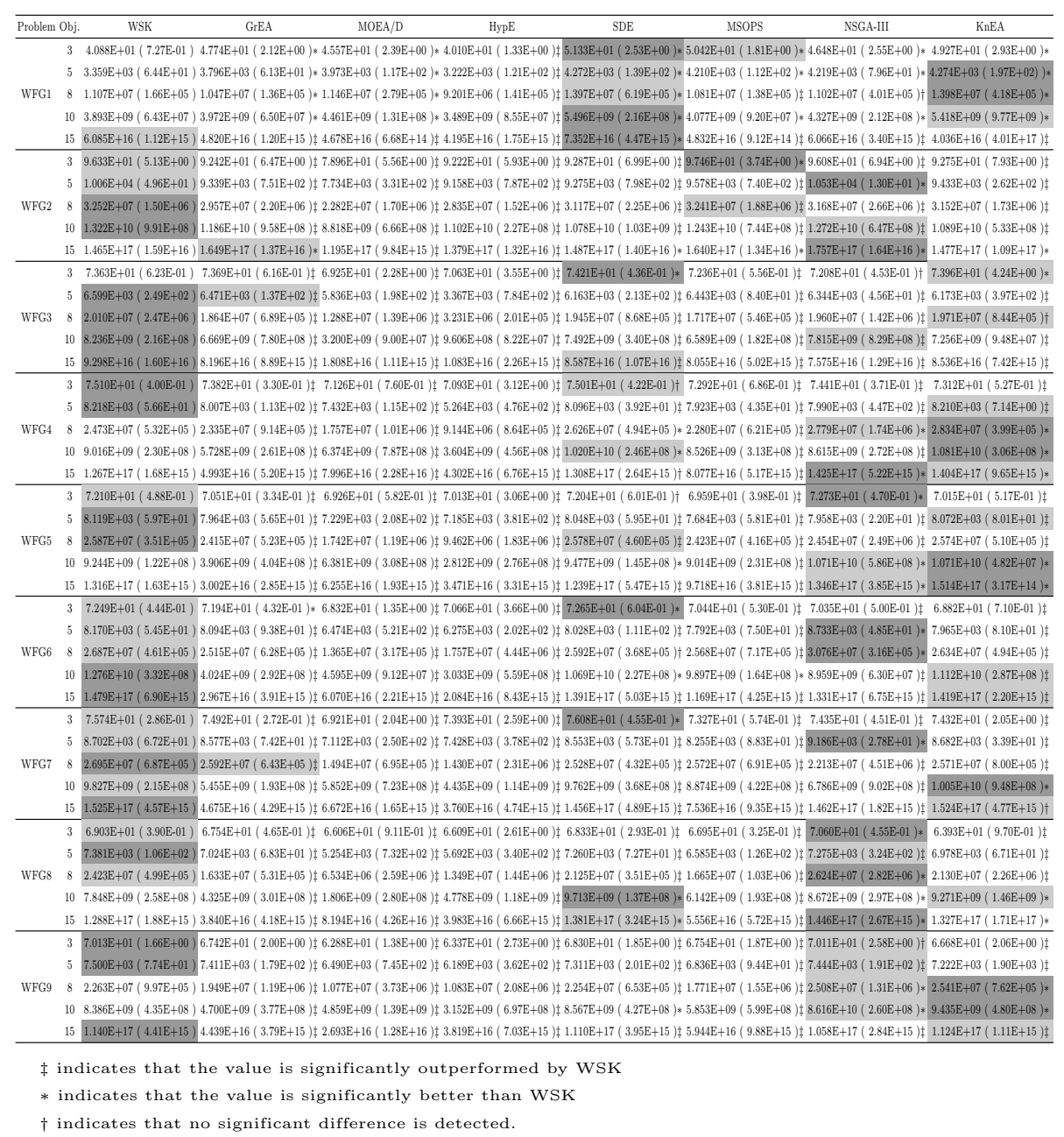

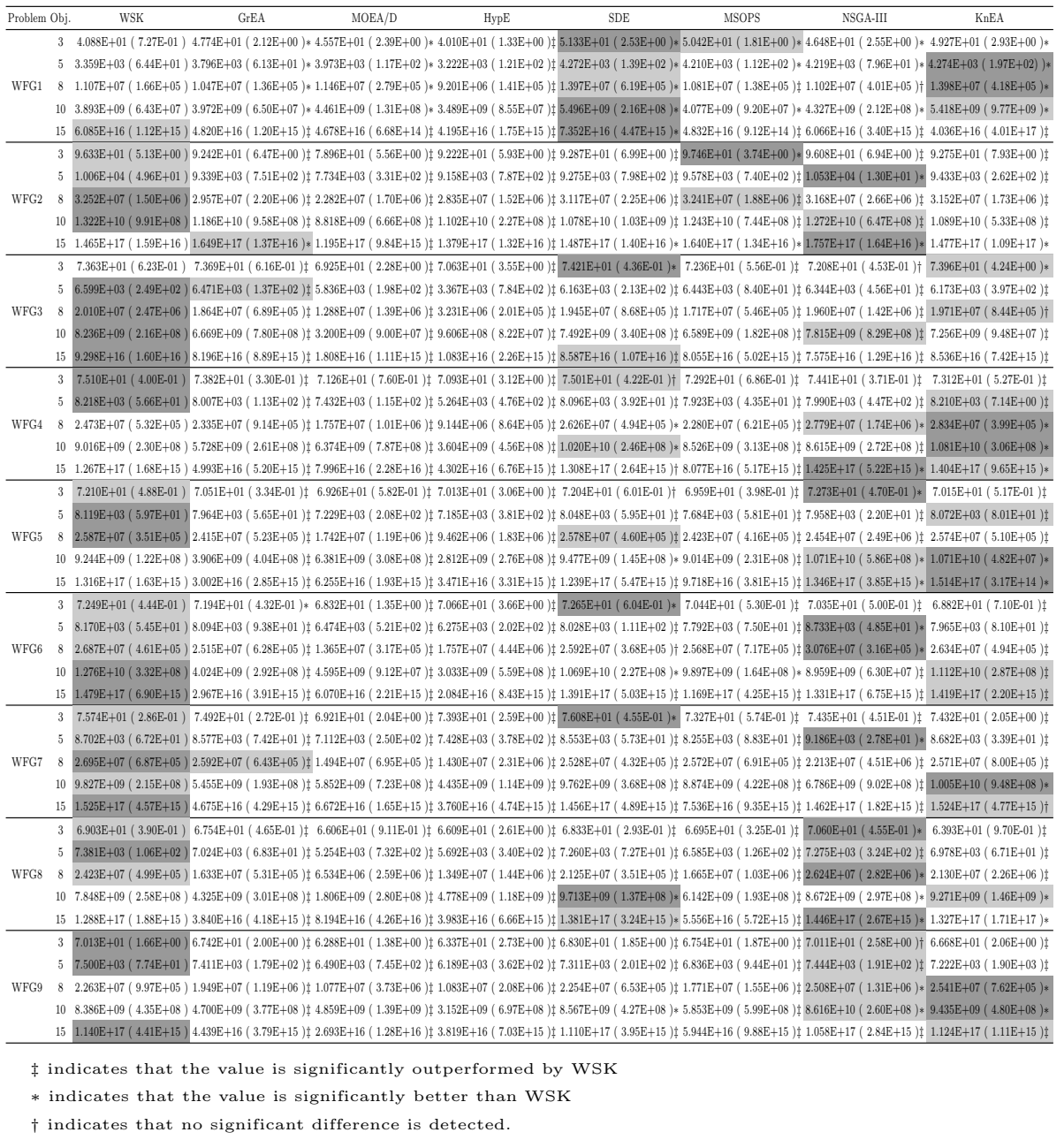

As in previous work, we compared the performance of these algorithms on the seven DTLZ test problems in terms of IGD. From Table 3 , some contrasting results can be observed. WSK performed well on DTLZ2, DTLZ3 and DTLZ4. For DTLZ1, WSK achieved the best IGD only on 5-objective problems. This 


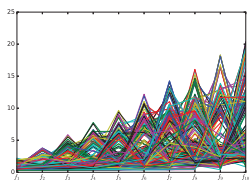

(a) WSK

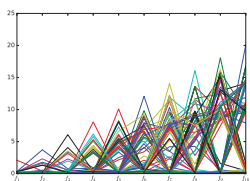

(e) $\mathrm{SDE}$

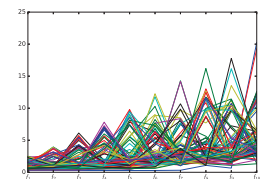

(b) GrEA

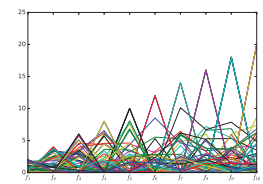

(f) MSOPS

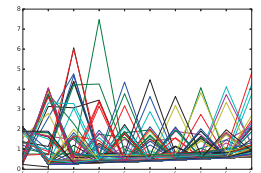

(c) MOEA/D

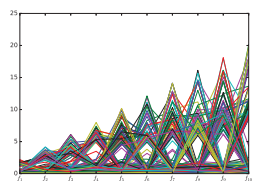

(g) NSGA-III

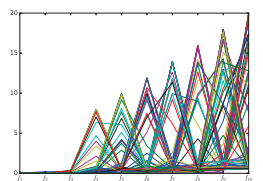

(d) HypE

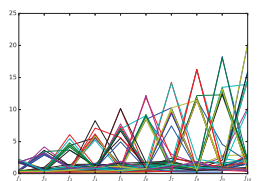

(g) KnEA

Figure 8: Final solution set of the seven algorithms on the 10-objective WFG9, shown by parallel coordinates.
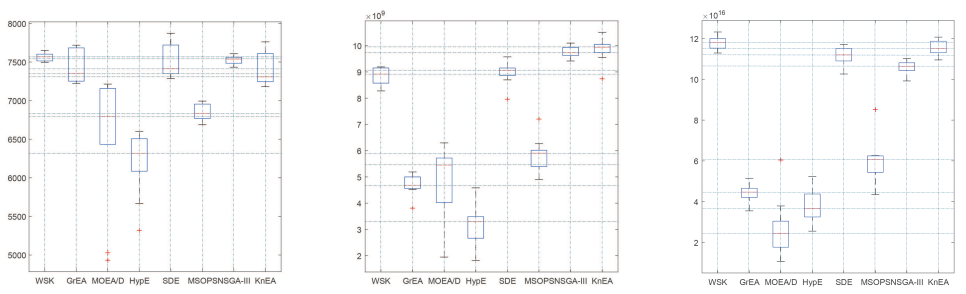

Figure 9: Final solution set of the seven algorithms on the 5, 10, 15-objective WFG9, shown by box plots. 
occurrence may be attributed to the flat PF. Although the subpopulation was divided by weight, the calculation of the distance between the solution to the hyperplane may still be affected by the PF. WSK achieved the best and second best IGD values on DTLZ2, DTLZ3 and DTLZ4. Among the DTLZ test problems, DTLZ5 and DTLZ6 are considered to be degenerated problems. The performance of WSK was general in DTLZ5 and DTLZ6. MOEA/D, SDE, MSOPS and NSGA-III performed well on DTLZ5 and DTLZ6. This occurrence may be attributed to the selection of the knee point. Although the knee point represents the critical point in the subpopulation, the weight allocated on the $\mathrm{PF}$ is very limited to degradation. For DTLZ7, WSK achieved the best IGD value on 5 objectives and second best IGD value on 3 objectives. GrEA and SDE performed well on DTLZ7.

Table 3: IGD (mean and standard deviation) results of the five algorithms on the DTLZ suites, where the best mean is shown with a deep gray background and the second best with a light gray background.

\begin{tabular}{|c|c|c|c|c|c|c|c|c|c|}
\hline roblem & & WSK & GrEA & MOEA/D & HypE & SDE & MSOPS & NSGA-III & KnEA \\
\hline & 3 & $2(9$ & $2(1$ & & $02(7$ & $02(2$ & $2.813 \mathrm{E}-02(4.75 \mathrm{E}-04$ & $1.920 \mathrm{E}-01(5.71 \mathrm{E}-05) *$ & $3.875 \mathrm{E}-02(3.04 \mathrm{E}-03$ \\
\hline & 5 & $5.391 \mathrm{E}-02(1.88 \mathrm{E}-03)$ & $6.835 \mathrm{E}-02(1.47 \mathrm{E}-02) \neq$ & $6.175 \mathrm{E}-02(1.63 \mathrm{E}-04) \ddagger$ & $(6.53 \mathrm{E}-03) \ddagger$ & $6.231 \mathrm{E}-02(5.94 \mathrm{E}-04) \ddagger$ & $8.036 \mathrm{E}-02(7.26 \mathrm{E}-04)$ & $5.876 \mathrm{E}-02(1.34 \mathrm{E}-02) \neq$ & $1.903 \mathrm{E}-01(1.38 \mathrm{E}+00) \neq$ \\
\hline \multirow[t]{5}{*}{ TLZ1 } & 8 & $1.279 \mathrm{E}-01(1.22 \mathrm{E}-01)$ & $1.077 \mathrm{E}-01(7.89 \mathrm{E}-03) *$ & $1.088 \mathrm{E}-01(6.39 \mathrm{E}-04) *$ & $3.610 \mathrm{E}+01(2.52 \mathrm{E}+00) \neq$ & $8.695 \mathrm{E}-02(1.80 \mathrm{E}-03) *$ & $1.267 \mathrm{E}-01(8.75 \mathrm{E}-04) \dagger$ & $1.101 \mathrm{E}-01(8.89 \mathrm{E}-02) *$ & $5.801 \mathrm{E}-01(2.62 \mathrm{E}-01) \ddagger$ \\
\hline & 10 & $1.417 \mathrm{E}-01(1.25 \mathrm{E}-02)$ & $2.684 \mathrm{E}-01(1.40 \mathrm{E}-01) \neq$ & $9.655 \mathrm{E}-02(2.38 \mathrm{E}-04) *$ & 3.88 & 1.174 $-01(2.90 \mathrm{E}$ & $1.468 \mathrm{E}-01(9.50 \mathrm{E}-04) \ddagger$ & $9.522 \mathrm{E}-02(1.09 \mathrm{E}-01)$ & $6.166 \mathrm{E}+00(2.04 \mathrm{E}+00) \neq$ \\
\hline & 15 & $4.732 \mathrm{E}-01(1.51 \mathrm{E}-02)$ & $3.521 \mathrm{E}+01(3.53 \mathrm{E}+01) \neq$ & $1.393 \mathrm{E}-01(2.37 \mathrm{E}-03) *$ & $4.249 \mathrm{E}-01(1.34 \mathrm{E}-01) *$ & $1.497 \mathrm{E}-01(1.89 \mathrm{E}-03) *$ & $1.706 \mathrm{E}-01(1.91 \mathrm{E}-03) *$ & $7.082 \mathrm{E}-02(2.96 \mathrm{E}-01) *$ & $9.005 \mathrm{E}+00(1.11 \mathrm{E}+01) \neq$ \\
\hline & 3 & $5.402 \mathrm{E}-02(1.12 \mathrm{E}-04)$ & $5.779 \mathrm{E}-02(1.08 \mathrm{E}-03) \neq$ & $5.425 \mathrm{E}-02(4.62 \mathrm{E}-06) \neq$ & $1.875 \mathrm{E}-01(2.42 \mathrm{E}-02) \neq$ & $7.215 \mathrm{E}-02(2.95 \mathrm{E}-03) \ddagger$ & $7.258 \mathrm{E}-02(3.68 \mathrm{E}-04) \neq$ & $5.396 \mathrm{E}-02(1.08 \mathrm{E}-04) \dagger$ & $6.991 \mathrm{E}-02(7.43 \mathrm{E}-02) \ddagger$ \\
\hline & 5 & $1.322 \mathrm{E}-01(2.22 \mathrm{E}-04)$ & $\mathrm{E}-01(1.46 \mathrm{E}-03) \ddagger$ & $1.579 \mathrm{E}-01(2.18 \mathrm{E}-04) \ddagger$ & $4.159 \mathrm{E}-01(2.27 \mathrm{E}-02) \neq$ & $1.804 \mathrm{E}-01(9.85 \mathrm{E}-03) \ddagger$ & $1.901 \mathrm{E}-01(3.99 \mathrm{E}-03) \neq$ & $1.348 \mathrm{E}-01(1.81 \mathrm{E}-03) \ddagger$ & $1.739 \mathrm{E}-01(5.02 \mathrm{E}-01) \ddagger$ \\
\hline \multirow[t]{5}{*}{ DTLZ2 } & 8 & $3.751 \mathrm{E}-01(2.90 \mathrm{E}-03)$ & $3.965 \mathrm{E}-01(3.67 \mathrm{E}-03) \ddagger$ & $4.497 \mathrm{E}-01(7.08 \mathrm{E}-04) \ddagger$ & $6.753 \mathrm{E}-01(1.16 \mathrm{E}-02) \neq$ & $4.479 \mathrm{E}-01(4.58 \mathrm{E}-03) \ddagger$ & $4.177 \mathrm{E}-01(2.38 \mathrm{E}-03) \neq$ & $3.699 \mathrm{E}-01(1.39 \mathrm{E}-03) *$ & $5.467 \mathrm{E}-01(1.57 \mathrm{E}-01) \neq$ \\
\hline & 10 & & $(4.3$ & $4.209 \mathrm{E}-01(5.59 \mathrm{E}-$ & 8.0291 & & 11 ( 2. & $5.194 \mathrm{E}-01(1$ & $4.252 \mathrm{E}-01(4.68 \mathrm{E}-03) *$ \\
\hline & & $6.377 \mathrm{E}-01(2.68 \mathrm{E}-03)$ & $1.134 \mathrm{E}+00(1.46 \mathrm{E}-01) \neq$ & $6.527 \mathrm{E}-01(2.90 \mathrm{E}-02) \neq$ & $1.051 \mathrm{E}+00(2.36 \mathrm{E}-02) \neq$ & $6.966 \mathrm{E}-01(6.92 \mathrm{E}-03) \ddagger$ & $6.304 \mathrm{E}-01(6.03 \mathrm{E}-03) *$ & $1.083 \mathrm{E}+00(2.34 \mathrm{E}-02) \neq$ & $6.482 \mathrm{E}-01(1.53 \mathrm{E}-02) \ddagger$ \\
\hline & 3 & $7.063 \mathrm{E}-02(3.67$ & $8.208 \mathrm{E}-02(1.03 \mathrm{E}-02)$ & $5.039 \mathrm{E}-02(2.00 \mathrm{E}-04) *$ & $2.316 \mathrm{E}-01(6.07 \mathrm{E}-02) \neq$ & $38 \mathrm{E}-02(3.02 \mathrm{E}-03) \ddagger$ & $7.247 \mathrm{E}-02(6.32 \mathrm{E}-04$ & $5.036 \mathrm{E}-02(9.10 \mathrm{E}-05) *$ & $8.050 \mathrm{E}-02(1.33 \mathrm{E}-04) \ddagger$ \\
\hline & 5 & $1.507 \mathrm{E}-01(5.13 \mathrm{E}-03)$ & $3.469 \mathrm{E}-01(2.80 \mathrm{E}-01) \neq$ & $1.592 \mathrm{E}-01(5.82 \mathrm{E}-04) \neq$ & $1.855 \mathrm{E}+02(5.66 \mathrm{E}+01) \neq$ & $1.898 \mathrm{E}-01(5.55 \mathrm{E}-03) \neq$ & $1.837 \mathrm{E}-01(3.79 \mathrm{E}-03) \neq$ & $1.618 \mathrm{E}-01(3.77 \mathrm{E}-02) \ddagger$ & $4.589 \mathrm{E}-01(6.12 \mathrm{E}-02) \ddagger$ \\
\hline \multirow[t]{5}{*}{ rLZ3 } & 8 & $4.299 \mathrm{E}-01(8.90 \mathrm{E}-03)$ & $7.677 \mathrm{E}-01(2.16 \mathrm{E}-01) \neq$ & $6.704 \mathrm{E}-01(2.79 \mathrm{E}-01) \neq$ & $\mathrm{E}+02(7.93 \mathrm{E}+00)$ & $(1.37 \mathrm{E}-0.0$ & $1(3$ & 4.480E-01 (1.48E+00 & $6.286 \mathrm{E}+01(8.40 \mathrm{E}+00) \neq$ \\
\hline & & 4.640E-01 (5.13E-03) & $7.191 \mathrm{E}-01(2.46 \mathrm{E}-01) \neq$ & 9.3 & & If & 0.415 & 9. & $(1.01 \mathrm{E}+02) \ddagger$ \\
\hline & 15 & $8.694 \mathrm{E}-01(3.28 \mathrm{E}-02)$ & $1.877 \mathrm{E}+02(5.77 \mathrm{E}+01) \neq$ & $1.069 \mathrm{E}+00(2.58 \mathrm{E}-01) \neq$ & $1.233 \mathrm{E}+02(5.37 \mathrm{E}+01) \pm$ & $7.423 \mathrm{E}-01(8.81 \mathrm{E}-03) *$ & $1.820 \mathrm{E}+00(9.40 \mathrm{E}-01) \neq$ & $1.071 \mathrm{E}+00(2.08 \mathrm{E}+01) \neq$ & $4.152 \mathrm{E}+02(1.52 \mathrm{E}+02) \ddagger$ \\
\hline & 3 & $5.425 \mathrm{E}-02(1.94)$ & $7.775 \mathrm{E}-02(1.62 \mathrm{E}-03) \ddagger$ & $4.867 \mathrm{E}-01(4.48 \mathrm{E}-01) \neq$ & $2.036 \mathrm{E}-01(1.72 \mathrm{E}-01) \ddagger$ & $6.904 \mathrm{E}-02(2.73 \mathrm{E}-01) \ddagger$ & $7.335 \mathrm{E}-02(1.84 \mathrm{E}-04) \neq$ & $2.696 \mathrm{E}-01(2.81 \mathrm{E}-01) \ddagger$ & $9.203 \mathrm{E}-02(2.81 \mathrm{E}-03) \neq$ \\
\hline & 5 & $1.331 \mathrm{E}-01(3.67 \mathrm{E}-04)$ & $1.854 \mathrm{E}-01(3.91 \mathrm{E}-02) \neq$ & $4.475 \mathrm{E}-01(3.08 \mathrm{E}-01) \ddagger$ & $3.658 \mathrm{E}-01(7.34 \mathrm{E}-02) \neq$ & $1.761 \mathrm{E}-01(1.22 \mathrm{E}-01) \ddagger$ & $1.918 \mathrm{E}-01(4.42 \mathrm{E}-03$ & $1.650 \mathrm{E}-01(1.90 \mathrm{E}-01) \ddagger$ & $2.246 \mathrm{E}-01(3.37 \mathrm{E}-03) \neq$ \\
\hline \multirow[t]{5}{*}{ TLZ4 } & & 3.853E-01 (3.94E-03) & $3.997 \mathrm{E}-01(3.58 \mathrm{E}-03) \ddagger$ & $7.342 \mathrm{E}-01(1.73 \mathrm{E}-01) \neq$ & $7.423 \mathrm{E}-01(3.47 \mathrm{E}-02) \neq$ & $4.584 \mathrm{E}-01(4.40 \mathrm{E}-02) \ddagger$ & $4.300 \mathrm{E}-01(2.40 \mathrm{E}-03) \neq$ & $4.818 \mathrm{E}-01(3.52 \mathrm{E}-01) \ddagger$ & $5.525 \mathrm{E}-01(4.93 \mathrm{E}-03) \ddagger$ \\
\hline & & $4.681 \mathrm{E}-01(1.66 \mathrm{E}-03)$ & $4.903 \mathrm{E}-01(3.33 \mathrm{E}-03) \neq$ & $8.345 \mathrm{E}-01(1.44 \mathrm{E}-01) \neq$ & $7.856 \mathrm{E}-01(1.59 \mathrm{E}-02) \neq$ & $5.614 \mathrm{E}-01(2.33 \mathrm{E}-02)$ & $5.137 \mathrm{E}-01(2.44 \mathrm{E}-03) \neq$ & 4.454E-01 (2. & 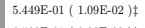 \\
\hline & 15 & $6.485 \mathrm{E}-01(4.51 \mathrm{E}-04)$ & $1.426 \mathrm{E}+00(9.40 \mathrm{E}-02) \neq$ & $9.917 \mathrm{E}-01(1.58 \mathrm{E}-01) \ddagger$ & $8.518 \mathrm{E}-01(1.90 \mathrm{E}-02) \neq$ & $7.165 \mathrm{E}-01(5.58 \mathrm{E}-03) *$ & $6.630 \mathrm{E}-01(4.04 \mathrm{E}-03) \neq$ & $4.039 \mathrm{E}-01(1.29 \mathrm{E}-01) *$ & $6.582 \mathrm{E}-01(2.20 \mathrm{E}-03) \ddagger$ \\
\hline & 3 & $3.464 \mathrm{E}-02(2.08 \mathrm{E}-03)$ & $1.309 \mathrm{E}-02(6.74 \mathrm{E}-04) *$ & $3.199 \mathrm{E}-02(1.09 \mathrm{E}-04) *$ & $3.518 \mathrm{E}-02(7.73 \mathrm{E}-03) *$ & $8.889 \mathrm{E}-03(5.98 \mathrm{E}-04) \ddagger$ & $2.000 \mathrm{E}-02(1.38 \mathrm{E}-04)$ & $1.591 \mathrm{E}-02(4.79 \mathrm{E}-03$ & $8.726 \mathrm{E}-03(5.70 \mathrm{E}-03) *$ \\
\hline & 5 & $1.058 \mathrm{E}-01(4.97 \mathrm{E}-02)$ & $3.634 \mathrm{E}-02(1.45 \mathrm{E}-02) \ddagger$ & $2.931 \mathrm{E}-02(2.65 \mathrm{E}-04) *$ & $1.783 \mathrm{E}-01(6.07 \mathrm{E}-02) \neq$ & $189 \mathrm{E}-02(1.10 \mathrm{E}-0$ & $2.360 \mathrm{E}-02(5.11$ & $(6$ & $2.238 \mathrm{E}-01(7.84 \mathrm{E}-01) \ddagger$ \\
\hline \multirow[t]{5}{*}{ rLZ: } & & $1.334 \mathrm{E}-01(2.72 \mathrm{E}-02)$ & $2.208 \mathrm{E}-01(3.73 \mathrm{E}-02) \ddagger$ & $6.731 \mathrm{E}-02(9.91 \mathrm{E}-05) *$ & $5.365 \mathrm{E}-01(1.23 \mathrm{E}-01) \neq$ & $1.121 \mathrm{E}-01(2.96 \mathrm{E}-02)$ & $1.940 \mathrm{E}-02(9.05 \mathrm{E}-03$ & ( $3.00 \mathrm{E}-01) \ddagger$ & 3.80 \\
\hline & 10 & $1.349 \mathrm{E}-01(3.70 \mathrm{E}-02)$ & $3.408 \mathrm{E}-01(5.52 \mathrm{E}-02) \ddagger$ & $5.033 \mathrm{E}-02(6.29 \mathrm{E}-03) *$ & $4.856 \mathrm{E}-01(9.27 \mathrm{E}-02) \neq$ & $1.334 \mathrm{E}-01(3.18 \mathrm{E}-02) \ddagger$ & $2.956 \mathrm{E}-02(3.15 \mathrm{E}-02) *$ & $1.398 \mathrm{E}-01(2.27 \mathrm{E}-01) \neq$ & $6.867 \mathrm{E}-01(7.27 \mathrm{E}-01) \ddagger$ \\
\hline & 15 & $1.755 \mathrm{E}-01(6.32 \mathrm{E}-02)$ & $6.347 \mathrm{E}-01(1.02 \mathrm{E}-01) \ddagger$ & $1.535 \mathrm{E}-01(4.16 \mathrm{E}-05) *$ & $4.440 \mathrm{E}-01(1.27 \mathrm{E}-01) \ddagger$ & $1.605 \mathrm{E}-01(2$. & $1.319 \mathrm{E}-01(6.81 \mathrm{E}-02) *$ & $2.114 \mathrm{E}-01(1.11 \mathrm{E}-01) \neq$ & $9.984 \mathrm{E}-01(4.74 \mathrm{E}+00) \ddagger$ \\
\hline & 3 & $8.045 \mathrm{E}-02(1.48 \mathrm{E}-02)$ & $4.125 \mathrm{E}-02(7.35 \mathrm{E}-03) *$ & $5.870 \mathrm{E}-02(9.64 \mathrm{E}-03) *$ & $1.434 \mathrm{E}-01(4.62 \mathrm{E}-02) \ddagger$ & $3.539 \mathrm{E}-02(7.37 \mathrm{E}-03) *$ & $5.789 \mathrm{E}-02(1.06 \mathrm{E}-02) *$ & $6.095 \mathrm{E}-02(6.26 \mathrm{E}-03) *$ & $6.370 \mathrm{E}-02(1.05 \mathrm{E}+01) *$ \\
\hline & & $3.498 \mathrm{E}-01(1.72 \mathrm{E}-02)$ & $2.776 \mathrm{E}-01(3.06 \mathrm{E}-01) *$ & $8.290 \mathrm{E}-02(1.66 \mathrm{E}-02) *$ & $2.633 \mathrm{E}+00(8.57 \mathrm{E}-02) \neq$ & $1.127 \mathrm{E}-01(1.18 \mathrm{E}-02) *$ & $4.126 \mathrm{E}-01(3.70 \mathrm{E}-02) \ddagger$ & $4.818 \mathrm{E}-01(1.54 \mathrm{E}-01) \neq$ & $8.830 \mathrm{E}-01(4.83 \mathrm{E}+00) \ddagger$ \\
\hline \multirow[t]{5}{*}{ TLZ6 } & & $4.558 \mathrm{E}-1$ & $7.830 \mathrm{E}-01(9.28 \mathrm{E}-01) \neq$ & $(1.51 \mathrm{E}-02) *$ & $(1.92 \mathrm{E}-01)+2$ & $(2.67 \mathrm{E}-02)$ & ( $5.02 \mathrm{E}-01$ & 9.578 & :492E-01 $(5.53 \mathrm{E}+00) \neq$ \\
\hline & & & $+00) \ddagger$ & 1.209E-01 (2. & & & & & .191 \\
\hline & 15 & 465 & $3.948 \mathrm{E}+00(1.23 \mathrm{E}+00) \neq$ & $2.078 \mathrm{E}-\mathrm{C}$ & $2.672 \mathrm{E}+$ & (6. 6. & $3.560 \mathrm{E}+00(4.06$ & 4.070 & 1.483 \\
\hline & 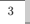 & & 9.9711 & 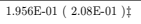 & $02) \neq 5$ & 5.845E-02 (9.46E-02)* & $.01(1.42 \mathrm{E}-02) \ddagger$ & $-02) \neq$ & $.600 \mathrm{E}-02(6.61 \mathrm{E}-01) \neq$ \\
\hline & & $3.108 \mathrm{E}-01(2.58 \mathrm{E}-02)$ & $3.169 \mathrm{E}-01(8.78 \mathrm{E}-03) \ddagger$ & $(4.22 \mathrm{E}-01) \ddagger$ & $+00(3.78 \mathrm{E}-01) \neq$ & $3.675 \mathrm{E}-01(1.63 \mathrm{E}-$ & $1(3.06 \mathrm{E}-02) \neq$ & $(3.28 \mathrm{E}-01) \ddagger$ & $4.498 \mathrm{E}-01(8.55 \mathrm{E}-02) \ddagger$ \\
\hline \multirow[t]{3}{*}{ LZZ } & & & & & & & & & \\
\hline & 10 & & & & & & & & \\
\hline & & & & & & & & & \\
\hline
\end{tabular}

To visualize the performance of algorithms in high-dimensional objective space, the final solution set of the seven algorithms is shown by parallel coor- 


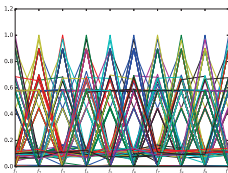

(a) WSK

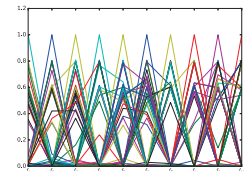

(e) $\mathrm{SDE}$

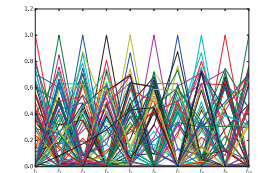

(b) GrEA

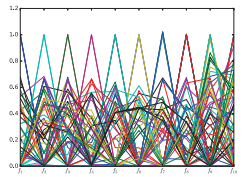

(f) MSOPS

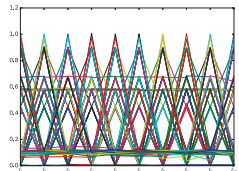

(c) MOEA/D

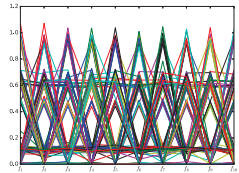

(g) NSGA-III

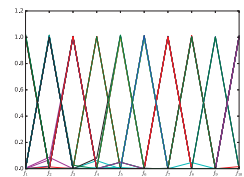

(d) $\mathrm{HypE}$

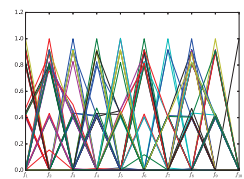

(g) KnEA

Figure 10: Final solution set of the seven algorithms on the 10-objective DTLZ2, shown by parallel coordinates.
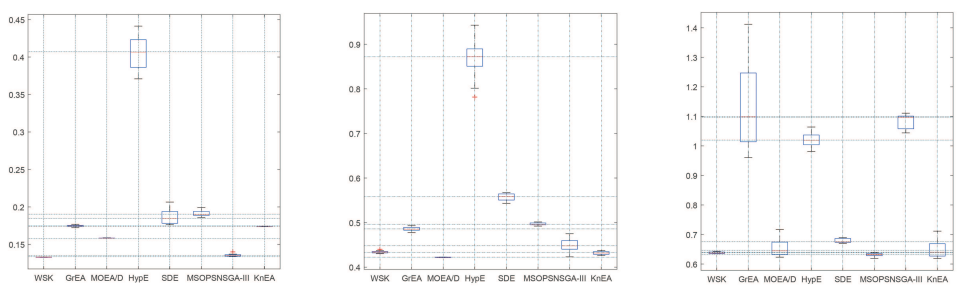

Figure 11: Final solution set of the seven algorithms on the 5, 10, 15-objective DTLZ2, shown by box plots. 
dinates. The lines with different colors represent different individuals in the figure, so that information can be easily acquired by readers. Figure 8 shows the final solution set of the WSK, GrEA, MOEA/D, HypE, SDE, MSOPS and NSGA-III on the 10-objective WFG9. Clearly, for this problem, WSK has a set of excellently distributed solutions over the PF; NSGA-III and SDE were slightly worse than WSK, and other algorithms were unable to maintain uniformity in their solutions. Figure 10 gives the final solution obtained by WSK, GrEA, MOEA/D, HypE, SDE, MSOPS and NSGA-III on the 10-objective DTLZ2. For this problem, WSK and NSGA-III have a set of excellently distributed solutions on the PF, HypE is unable to maintain uniformity of the solutions, and other algorithms performed well in maintaining distribution.

Box plots are shown Figure 9 and Figure 11, where the plus sign represents the extreme solution; the short line represents the range of all solutions; the red line represents the mean value, and the rectangle represents the range of most solutions except for the extreme solution. The smaller the rectangle is, the more stable the algorithm is. In Figure 9 and Figure 11 . WSK has a minimal rectangle, indicating that WSK is a stable algorithm. In Figure 9, WSK achieved a best mean value and best stability on the 5-objective and 15-objective problems. NSGA-III achieved the best mean value on the 10-objective problems. For DTLZ2, WSK obtained the best mean value on the 5-objective problems. MOEA/D obtained the best mean value on 10-objective problems. MSOPS obtained the best mean value on 15 objectives.

From Table 2 and Table 3 , we can see WSK achieved the best HV in eighteen test instances and second best HV in twelve out of forty-five WFG test instances. Furthermore, WSK achieved the best IGD in nine test instances and the second best IGD in seven out of 35 DTLZ test instances. As a whole, WSK performed better than the other algorithms.

As shown in tables 2 and 3, the best performance of WSK appears in the problems DTLZ2-DTLZ4 and WFG4-WFG9. Specifically, WSK is good at these kinds of problems. Although having various properties, these problems have the same PF, which has a spherical shape. The reason for the better performance 
Table 4: IGD (mean and standard deviation) results of the five algorithms on the ZDT suites, where the best mean is shown with a deep gray background and the second best with a light gray background.

\begin{tabular}{|c|c|c|c|c|c|c|c|}
\hline Problem & WSK & GrEA & $\mathrm{MOEA} / \mathrm{D}$ & HypE & SDE & NSGA-III & KnEA \\
\hline ZDT1 & $8.522 \mathrm{E}-02(2.14 \mathrm{E}-03)$ & $1.899 \mathrm{E}-01(7.70 \mathrm{E}-03) \ddagger$ & $1.203 \mathrm{E}-01(3.34 \mathrm{E}-04) \ddagger$ & $5.246 \mathrm{E}-01(2.10 \mathrm{E}-03) \ddagger$ & $8.679 \mathrm{E}-02(2.22 \mathrm{E}-03) \ddagger$ & $8.492 \mathrm{E}-01(1.03 \mathrm{E}-01) \ddagger 5.674 \mathrm{E}-01(4.05 \mathrm{E}-02) \ddagger$ & $2.765 \mathrm{E}-01(8.73 \mathrm{E}-03) \ddagger$ \\
\hline ZDT2 & $2.483 \mathrm{E}-01(3.70 \mathrm{E}-03)$ & $4.605 \mathrm{E}-01(1.92 \mathrm{E}-02) \ddagger$ & $4.225 \mathrm{E}-01(4.58 \mathrm{E}-02) \ddagger$ & $6.339 \mathrm{E}-01(5.95 \mathrm{E}-03) \ddagger$ & $4.092 \mathrm{E}-01(1.00 \mathrm{E}-02) \ddagger$ & $1.149 \mathrm{E}+00(1.45 \mathrm{E}-01) \ddagger 1.112 \mathrm{E}+00(1.27 \mathrm{E}-01) \ddagger$ & $4.254 \mathrm{E}-01(4.13 \mathrm{E}-02) \ddagger$ \\
\hline ZDT3 & $2.293 \mathrm{E}-01(4.91 \mathrm{E}-03)$ & $1.776 \mathrm{E}-01(8.20 \mathrm{E}-03) *$ & $1.565 \mathrm{E}-01(3.29 \mathrm{E}-03) *$ & 4.947E-01(8.17E-03) $\ddagger$ & $1.054 \mathrm{E}-01(1.04 \mathrm{E}-03) *$ & $8.377 \mathrm{E}-01(6.66 \mathrm{E}-02) \ddagger \quad 4.132 \mathrm{E}-01(1.06 \mathrm{E}-01) \ddagger$ & $2.472 \mathrm{E}-01(9.95 \mathrm{E}-03) \ddagger$ \\
\hline ZDT4 & $1.283 \mathrm{E}-01(1.74 \mathrm{E}-03)$ & $2.410 \mathrm{E}-01(1.41 \mathrm{E}-02) \ddagger$ & $5.739 \mathrm{E}-01(5.33 \mathrm{E}-02) \ddagger$ & $6.245 \mathrm{E}-01(1.32 \mathrm{E}-02) \ddagger$ & 1.280E-01(1.73E-03)* & $9.009 \mathrm{E}-01(1.29 \mathrm{E}-01) \ddagger \quad 4.825 \mathrm{E}-01(8.34 \mathrm{E}-02) \ddagger$ & $3.374 \mathrm{E}-01(4.14 \mathrm{E}-02) \ddagger$ \\
\hline ZDT5 & $1.167 \mathrm{E}+00(4.85 \mathrm{E}-02)$ & $3.173 \mathrm{E}+00(2.06 \mathrm{E}+00) \ddagger$ & $\mathrm{E}+00(3.45 \mathrm{E}-03$ & $0 \mathrm{E}+00(4.96 \mathrm{E}-02$ & $1.013 \mathrm{E}+00(3$ & $1.456 \mathrm{E}+00(3.00 \mathrm{E}-01$ & $6.075 \mathrm{E}+00(1.18 \mathrm{E}+00) \ddagger$ \\
\hline ZDT6 & $6.982 \mathrm{E}-02(3.27 \mathrm{E}-04)$ & $1.610 \mathrm{E}-01(9.84 \mathrm{E}-04) \ddagger$ & $1.050 \mathrm{E}-01(5.51 \mathrm{E}-04) \ddagger$ & $8.552 \mathrm{E}-02(1.33 \mathrm{E}-03) \ddagger$ & $7.022 \mathrm{E}-02(3.30 \mathrm{E}-04) \dagger$ & $2.477 \mathrm{E}-01(9.67 \mathrm{E}-03) \ddagger \quad 4.095 \mathrm{E}-01(3.18 \mathrm{E}-02) \ddagger$ & $1.045 \mathrm{E}-01(2.27 \mathrm{E}-03) \ddagger$ \\
\hline
\end{tabular}

Table 5: Statistical Result (mean and standard deviation) of the IGD value obtained by WSK* and WSK on DTLZ1 -DTLZ4,The best mean is shown with a deep gray background.

\begin{tabular}{ccccc}
\hline Problem Obj. & WSK* & WSK \\
\hline \multirow{2}{*}{ DTLZ1 } & 5 & $5.146 \mathrm{E}-02(7.72 \mathrm{E}-09)$ & $5.391 \mathrm{E}-02(1.88 \mathrm{E}-03) \ddagger$ \\
& 10 & $8.100 \mathrm{E}-02(1.65 \mathrm{E}-06)$ & $1.417 \mathrm{E}-01(1.25 \mathrm{E}-02) \ddagger$ \\
\hline \multirow{2}{*}{ DTLZ2 } & 15 & $1.535 \mathrm{E}-01(4.71 \mathrm{E}-06)$ & $4.732 \mathrm{E}-01(1.51 \mathrm{E}-02) \ddagger$ \\
& 10 & $4.254 \mathrm{E}-01(5.05 \mathrm{E}-06)$ & $4.339 \mathrm{E}-01(2.48 \mathrm{E}-03) \ddagger$ \\
& 15 & $6.356 \mathrm{E}-01(4.19 \mathrm{E}-06)$ & $6.377 \mathrm{E}-01(2.68 \mathrm{E}-03) \ddagger$ \\
\hline \multirow{2}{*}{ DTLZ3 } & 5 & $1.340 \mathrm{E}-01(8.95 \mathrm{E}-07)$ & $1.507 \mathrm{E}-01(5.13 \mathrm{E}-03) \ddagger$ \\
& 10 & $4.360 \mathrm{E}-01(9.07 \mathrm{E}-06)$ & $4.640 \mathrm{E}-01(5.13 \mathrm{E}-03) \ddagger$ \\
\hline & 5 & $6.465 \mathrm{E}-01(2.21 \mathrm{E}-04)$ & $8.694 \mathrm{E}-01(3.28 \mathrm{E}-02) \ddagger$ \\
DTLZ4 & 10 & $4.540 \mathrm{E}-01(1.38 \mathrm{E}-05)$ & $4.681 \mathrm{E}-01(1.66 \mathrm{E}-03) \ddagger$ \\
& 15 & $6.473 \mathrm{E}-01(5.84 \mathrm{E}-07)$ & $6.485 \mathrm{E}-01(4.51 \mathrm{E}-04) \ddagger$ \\
\hline
\end{tabular}


From Table 4 some contrasting results can be observed. WSK achieved the best and second-best IGD values on ZDT1, ZDT2, ZDT4 and ZDT6. The performance of WSK was general in ZDT3 and ZDT5. This occurrence may be attributed to the discrete and discontinuous properties of the test problems. In these problem, weight vectors have difficulty covering the whole PF regions accurately, so the knee point cannot guide the population direction.

\subsection{Discussion}

To illustrate the performance of WSK, it was compared to six other stateof-the-art MaEAs on a series of test problems. The experimental results on test problems with 3 to 15 objectives show that WSK is significantly better than GrEA, MSOPS, and MOEA/D, and is comparative with SDE and NSGA-III. In summary, given a large number of benchmark problems with various problem characteristics and the performance metrics IGD and HV, WSK ensures better performance in both convergence and diversity.

Meanwhile, the WSK with the normalization strategy removed (denoted as WSK* hereafter) is compared with the original WSK. To compare the performance of the solutions obtained by WSK* and WSK, the IGD indicator is used. As shown in Table 5. WSK* significantly outperformed the original WSK on DTLZ1-4. The major reason for the better performance of WSK* on these test problems is scaling of objective function. Since the association operation of algorithm does not consider the scaling of individuals, the dimensions with different scales will cause uneven distribution in the population. The accuracy of the association operation will be reduced.

\section{CONCLUSION}

In order to ensure excellent convergence and diversity in solving MaOPs, this paper has proposed an algorithm combining the advantages of decomposition and knee point. In WSK, the worst solution of the old population was replaced by the best solution in the new population. By repeating the update operation, a solution set with good performance was obtained. 
In addition, it is also worth mentioning that the performance of proposed WSK is related to the shape of the PF for a given multiobjective problem since a set of weights have different distributions on different shapes of PF. When the shape of the PF is convex, the weight tends to be more concentrated on the center of the PF; when the shape of the PF is concave, the weight tends concentrate more on the edges of the PF. Therefore, WSK is not good at solving convex problems because the number of solutions on the edge is difficult to maintain. However, this problem can be addressed by adjusting each dimension of weights (according to the extreme individual in the current population) before the association operation.

In the next stage, we will have a deeper insight into the weight adjustment of WSK, so as to further improve its performance. It would also be interesting to extend our WSK to solve the problems with convex traits. Moreover, we would apply WSK to real-world problems in order to further verify its effectiveness.

Studies on MOEAs have been carried out for many years. So far, many MOEAs have been proposed. These algorithms have important guiding significance for solving MOPs and practical research. In the study of MOEA, we need to fully understand the idea of the algorithm and grasp its strengths and weaknesses in order to provide a theoretical basis for further research.

\section{Acknowledgements}

The authors wish to thank the support of the National Natural Science Foundation of China (Grant No. 61876164, 61502408, 61673331), the Education Department Major Project of Hunan Province (Grant No. 17A212), The MOE Key Laboratory of Intelligent Computing and Information Processing, the Science and Technology Plan Project of Hunan Province (Grant No. 2016TP1020), the Provinces and Cities Joint Foundation Project (Grant No. 2017JJ4001), the Hunan province science and technology project funds(2018TP1036). 


\section{References}

[1] B. Li, J. Li, K. Tang, X. Yao, Many-objective evolutionary algorithms: A survey, Acm Computing Surveys 48 (1) (2015) 13.

[2] G. Fu, Z. Kapelan, J. R. Kasprzyk, P. Reed, Optimal design of water distribution systems using many-objective visual analytics, Journal of Water Resources Planning \& Management Asce 139 (6) (2013) 624-633.

[3] R. J. Lygoe, M. Cary, P. J. Fleming, A real-world application of a manyobjective optimisation complexity reduction process.

[4] P. J. Fleming, R. C. Purshouse, R. J. Lygoe, Many-objective optimization: An engineering design perspective, Lecture Notes in Computer Science 3410 (2005) 14-32.

[5] V. Khare, X. Yao, K. Deb, Performance scaling of multi-objective evolutionary algorithms, in: International Conference on Evolutionary MultiCriterion Optimization, 2003, pp. 376-390.

[6] K. Deb, A. Pratap, S. Agarwal, T. Meyarivan, A fast and elitist multiobjective genetic algorithm: Nsga-ii, IEEE Transactions on Evolutionary Computation 6 (2) (2002) 182-197.

[7] E. Zitzler, M. Laumanns, L. Thiele, Spea2: Improving the strength pareto evolutionary algorithm.

[8] D. W. Corne, N. R. Jerram, J. D. Knowles, M. J. Oates, Pesa-ii: regionbased selection in evolutionary multiobjective optimization, in: Conference on Genetic and Evolutionary Computation, 2001, pp. 283-290.

[9] G. Ruan, G. Yu, J. Zheng, J. Zou, S. Yang, The effect of diversity maintenance on prediction in dynamic multi-objective optimization, Applied Soft Computing 58 (2017) 631-647.

[10] J. Zou, Y. Zhang, S. Yang, Y. Liu, J. Zheng, Adaptive neighborhood selection for many-objective optimization problems, Applied Soft Computing. 
[11] J. Zou, J. Zheng, R. Shen, C. Deng, A novel metric based on changes in pareto domination ratio for objective reduction of many-objective optimization problems, Journal of Experimental \& Theoretical Artificial Intelligence 29 (5) (2017) 1-12.

[12] J. Zou, L. Fu, S. Yang, J. Zheng, G. Yu, Y. Hu, A many-objective evolutionary algorithm based on rotated grid, Applied Soft Computing 67.

[13] L. Fu, J. Zou, S. Yang, R. Gan, Z. Ma, J. Zheng, A proportion-based selection scheme for multi-objective optimization, in: Computational Intelligence, 2018, pp. 1-7.

[14] D. Hadka, P. M. Reed, T. W. Simpson, Diagnostic assessment of the borg moea for many-objective product family design problems, in: Evolutionary Computation, 2012, pp. 1-10.

[15] H. Sato, H. E. Aguirre, K. Tanaka, Controlling Dominance Area of Solutions and Its Impact on the Performance of MOEAs, Springer Berlin Heidelberg, 2007.

[16] S. Yang, M. Li, X. Liu, J. Zheng, A grid-based evolutionary algorithm for many-objective optimization, IEEE Transactions on Evolutionary Computation 17 (5) (2013) 721-736.

[17] S. F. Adra, P. J. Fleming, Diversity management in evolutionary manyobjective optimization, IEEE Transactions on Evolutionary Computation 15 (2) (2011) 183-195.

[18] M. Li, S. Yang, X. Liu, Shift-based density estimation for pareto-based algorithms in many-objective optimization, IEEE Transactions on Evolutionary Computation 18 (3) (2014) 348-365.

[19] Y. Liu, D. Gong, S. Jing, Y. Jin, A many-objective evolutionary algorithm using a one-by-one selection strategy, IEEE Transactions on Cybernetics 47 (9) (2017) 2689-2702. 
[20] E. J. Hughes, Multiple single objective pareto sampling, in: Evolutionary Computation, 2003. CEC '03. The 2003 Congress on, 2004, pp. 2678-2684 Vol.4.

[21] T. Ray, M. Asafuddoula, A. Isaacs, A steady state decomposition based quantum genetic algorithm for many objective optimization, in: Evolutionary Computation, 2013, pp. 2817-2824.

[22] Q. Zhang, H. Li, Moea/d: A multiobjective evolutionary algorithm based on decomposition, IEEE Transactions on Evolutionary Computation 11 (6) (2007) 712-731.

[23] J. Bader, E. Zitzler, Hype: An algorithm for fast hypervolume-based manyobjective optimization, Evolutionary Computation 19 (1) (2014) 45-76.

[24] M. Emmerich, N. Beume, B. Naujoks, An emo algorithm using the hypervolume measure as selection criterion, in: International Conference on Evolutionary Multi-Criterion Optimization, 2005, pp. 62-76.

[25] E. Zitzler, S. Knzli, Indicator-Based Selection in Multiobjective Search, 2004.

[26] K. Deb, H. Jain, An evolutionary many-objective optimization algorithm using reference-point-based nondominated sorting approach, part i: Solving problems with box constraints, IEEE Transactions on Evolutionary Computation 18 (4) (2014) 577-601.

[27] B. Li, J. Li, K. Tang, X. Yao, An improved two archive algorithm for manyobjective optimization, in: Evolutionary Computation, 2014, pp. 524-541.

[28] H. J. F. Moen, N. B. Hansen, H. Hovland, J. Trresen, Many-objective optimization using taxi-cab surface evolutionary algorithm, in: International Conference on Evolutionary Multi-Criterion Optimization, 2013, pp. 128142. 
[29] Y. Xiang, Y. Zhou, M. Li, Z. Chen, A vector angle-based evolutionary algorithm for unconstrained many-objective optimization, IEEE Transactions on Evolutionary Computation 21 (1) (2017) 131-152.

[30] H. K. Singh, A. Isaacs, T. Ray, A pareto corner search evolutionary algorithm and dimensionality reduction in many-objective optimization problems, IEEE Transactions on Evolutionary Computation 15 (4) (2011) 539556.

[31] J. Zou, J. Zheng, C. Deng, R. Shen, An evaluation of non-redundant objective sets based on the spatial similarity ratio, Soft Computing 19 (8) (2015) $2275-2286$.

[32] J. Branke, K. Deb, H. Dierolf, M. Osswald, Finding knees in multi-objective optimization (2004) 722-731.

[33] X. Zhang, Y. Tian, Y. Jin, A knee point-driven evolutionary algorithm for many-objective optimization, IEEE Transactions on Evolutionary Computation 19 (6) (2015) 761-776.

[34] S. Huband, P. Hingston, L. Barone, L. While, A review of multiobjective test problems and a scalable test problem toolkit., IEEE Transactions on Evolutionary Computation 10 (5) (2006) 477-506.

[35] K. Deb, L. Thiele, M. Laumanns, E. Zitzler, Scalable multi-objective optimization test problems, in: wcci, 2002, pp. 825-830.

[36] E. Zitzler, K. Deb, L. Thiele, Comparison of multiobjective evolutionary algorithms: Empirical results, Evolutionary Computation 8 (2) (2000) 173195.

[37] K. Deb, R. B. Agrawal, Simulated binary crossover for continuous search space 9 (3) (1994) 115-148.

[38] K. Deb, M. Goyal, A combined genetic adaptive search (geneas) for engineering design, 1996, pp. 30-45. 
[39] Q. Zhang, A. Zhou, Y. Jin, RM-MEDA: A Regularity Model-Based Multiobjective Estimation of Distribution Algorithm, IEEE Press, 2008.

[40] L. While, P. Hingston, L. Barone, S. Huband, A faster algorithm for calculating hypervolume, IEEE Transactions on Evolutionary Computation 10 (1) (2006) 29-38.

[41] E. Zitzler, J. Knowles, L. Thiele, Quality assessment of pareto set approximations, in: Multiobjective Optimization, 2008, pp. 373-404. 